\title{
Abnormalities in Semen Parameters of Men Due to Consumption of Alcohol
}

\author{
Kadiri Pullanna ${ }^{1}$, Dereddy Nagalinga Reddy ${ }^{2}$, Gundala Harold Philip ${ }^{3}$ \\ ${ }^{1,3}$ Department of Zoology, Sri Krishnadevaraya University, Ananthapuramu- 515 003, Andhra Pradesh, India \\ ${ }^{2}$ Principal, Government Degree College, Penukonda, Anantapuramu, Andhra Pradesh, India
}

\begin{abstract}
To investigate the effects of alcohol consumption on semen parameters, semen samples were collected from eighty (80) alcohol consumption men. This sample was from a cross section of population of Anantapuramu district, Andhra Pradesh, India. They were divided into two age groups namely 25-35 years and 35-45 years. In both age groups persons were selected basing as how many units of alcohol they consumed in a day. Different semen parameters like volume, liquefaction, alkalinity, sperm count, motility and morphology were analysed. Incidences of Hypospermia in 43, Teratozoospermia in 21, Oligozoospermia in 59, Oligoasthenozoospermia in 22 and Oligoasthenoteratozoopermia in 6 persons were observed. Abnormalities were seen in both age groups and was more pronounced in persons who consumed alcohol either moderately or heavily.
\end{abstract}

Keywords: Alcohol Consumption, Men, Reproductive health, Semen analysis.

\section{Introduction}

Male infertility plays a key role in conception difficulties of up to $40 \%$ infertile couples. Infertility, defined as the inability to conceive after 12 months of regular unprotected sexual intercourse, affects $10-15 \%$ of all couples [1], [2]. The known reasons for male infertility are hormonal disorder, hereditary diseases and chromosomal abnormalities, gonadotoxins (medicine, insecticides, radiation, magnetic fields, alcohol, smoking, drugs and food additives), abnormal spermatogenesis and various metabolic diseases [3]. Alcohol is one of the lifestyle factors that have effects on male reproduction.

Excessive alcohol consumption contributes to a variety of health and social problems, including unintentional injuries (e.g., injuries due to motor vehicle crashes), suicide, homicide, liver cirrhosis, gastrointestinal cancers, vandalism and lost productivity [4]. Alcohol consumption also contributes to the three leading causes of death (unintentional injuries, suicide and homicide) among adolescents [5]. Also any underage drinking is not acceptable.

Alcohol abuse is a major health issue and is responsible for 2.5 million deaths worldwide each year [6]. Consumption of alcohol causes several diseases, and it is the high burden of mortality around the world [6]. In addition, seminiferous tubules in alcohol users mostly contain degenerated spermatids with a consequent azoospermia [7]. These effects may be due to alteration of the endocrine system controlling the hypothalamic pituitary testicular (HPT) axis function and/or to a direct effect on testis and/or male accessory glands [7], [8], [9].

Modest habitual alcohol consumption of more than 5 units per week had adverse effects on semen quality although most pronounced associations were seen in men who consumed more than 25 units per week. Ethanol is a material which is regarded as a reproductive toxin [10]. Chronic consumption of ethanol by men causes atrophy in testicles, reduction in sperm production and drop in testosterone levels [11]. Chronic use of ethanol causes gonadal dysfunction; suppresses spermatogenic cases; reduces the proliferative activation of the spermatogoniums in every level of seminiferous tubule cycles [12], [13]. In particular, experimental evidence suggests that ethanol is a Leydig cell toxin [9], [14]. Alcohol was shown to have deleterious effect on testis and the consequent testicular damage along with decrease of sex hormones leads to a loss of secondary sexual characteristics followed by the onset of erectile dysfunction and infertility [15], [16]. Investigation of 34 healthy Argentine medical students who consumed alcohol had a non-significant reduction in sperm concentration, motility, viability and normal morphology [17]. Hence in the present study we evaluated the effects of alcohol consumption as a sample population between age group of 25-45 years in the district of Anantapuramu, Andhra Pradesh, India.

\section{Materials and Methods}

One hundred and fifty healthy human males, who consumed alcohol, were interviewed particularly regarding age and the number of years they were alcohol drinking. From this sample, eighty (80) persons were selected and divided into two age groups namely 25-35 years and 35-45 years. Each group consisted of forty (40) men. Out of this forty, twenty were moderate drinking ( $4 \pm 1$ Alcohol units/day) and twenty were heavy drinking ( $7 \pm 1$ Alcohol units/day). The study protocol was approved by the Institutional Animal Ethical Committee. Before enrollment in the study, written consent was obtained from volunteers.

The selected men were invited to clinical laboratory and semen sample was collected by masturbation and ejaculated into a clean wide mouth glass container. Care was taken to see that the sample was collected after a minimum of two days and maximum of seven days sexual abstinence. The semen sample collected was kept at room temperature $\left(20^{\circ} \mathrm{C}-37^{\circ} \mathrm{C}\right)$ to avoid any effect on spermatozoa. Container was labeled with person's name, identification number, date and time of collection. WHO guidelines were followed in 


\section{International Journal of Science and Research (IJSR) \\ ISSN (Online): 2319-7064 \\ Index Copernicus Value (2013): 6.14 | Impact Factor (2014): 5.611}

collection and analysis of semen sample [18]. The following investigations were carried out in the samples.

\subsection{Colour, volume and $\mathbf{p H}$}

Colour of the semen was observed immediately after collection and the volume was measured using graduated test tube. The semen reaction was observed by measuring its $\mathrm{pH}$.

\subsection{Liquefaction}

Immediately after ejaculation into the collection vessel, sample was kept at room temperature and time of liquefaction was observed up to $90 \mathrm{~min}$. Semen was typically a semisolid coagulated mass first and within a few minutes at room temperature, the semen usually begins to liquefy (become thinner). The time taken to liquefy was noted.

\subsection{Sperm Count and Motility}

Sperm count and motility were made using the above liquefied sample under the microscope. Total sperm count (Mill/ml) was calculated by using neubauer chamber [18]. Briefly the liquefied semen was diluted 1:20 with sodium carbonate and this diluted sample was placed on the neubauer chamber and counted under the microscope (Labomed). Motility was determined by counting the number of motile and immotile spermatozoa from the same slide in several randomly selected fields under 20X objective until at least 200 spermatozoa were counted. The minimum of five microscopic fields were examined.

\subsection{Sperm Morphology}

This was determined with the help of smears made from semen samples using feathering technique. A clean glass slide was taken, washed in $70 \%$ ethanol and dried. A small drop of semen (5 to $20 \mu \mathrm{l}$ ) was taken onto the slide. The edge of a second slide was placed on the first, at an angle of $45^{\circ}$ and the semen drop was dragged along the surface to make a thin smear. These were then air dried and fixed. Sperm morphology was evaluated using hematoxylin and eosin stain. Normal and the abnormal sperms were observed under 100X oil immersion microscope. Each of the spermatozoa was examined for head, mid-piece and tail defects. A total of 200 spermatozoa were observed for defects and expressed in percentage. Loose heads were counted (as abnormal forms), while free tails were not counted. Structures without any head anterior to the basal plate were not counted.

\section{Results}

Evaluation of semen analysis in men addicted to alcohol drinking are given in tables 1 to 3 . In this investigation we found that all men had white and alkaline semen. The volume of semen measured was less than the normal values in forty three (43) men out of eighty (80). In men who consumed moderate alcohol, eight persons in the age group of 25-35 and in heavy alcohol drinkers ten persons in the age group of 25-35 have shown hypospermia (Table 1). In men who consumed moderate alcohol, twelve persons in the age group of 35-45 and in heavy alcohol drinkers thirteen persons in the age group of 35-45 have shown hypospermia (Table 2).

Liquefaction time of semen observed in men of both groups was within the time given by WHO in all age groups (Table 1-2). With regard to sperm count it was less than the normal values in fifty eight (59) men out of eighty (80) men who were examined. In men who consumed moderate alcohol, fifteen persons in the age group of 25-35 and in heavy drinkers, sixteen persons in the age group of 25-35 have shown oligozoospermia (Table 1). In men who consumed moderate alcohol, thirteen persons in the age group of 35-45 and in heavy drinker men fifteen persons in the age group of 35-45 have shown oligozoospermia (Table 2).

Oligoasthenozoospermia have been noticed in twenty two men (22) out of eighty (80) men examined. In men who consumed moderate alcohol, four persons in the age group of 25-35 and in heavy drinkers group, eight in the age group of 25-35 have shown Oligoasthenozoospermia (Table 1). In men who consumed moderate alcohol, five persons in the age group of 35-45 and in heavy drinkers group, five persons in the age group of 35-45 have shown Oligoasthenozoospermia (Table 2).

Oligoasthenoteratozoospermia have been noticed in six men (6) out of eighty (80) men examined. In men who consumed moderate alcohol, one person in the age group of 25-35 and in heavy drinkers group, two persons in the age group of 2535 have shown Oligoasthenoteratozoospermia (Table 1). In men who consumed moderate alcohol, two persons in the age group of 35-45 and in heavy drinkers group, one person in the age group of 35-45 have shown Oligoasthenoteratozoospermia (Table 2).

Morphologically abnormal sperms have been noticed in twenty one men (21) out of eighty (80) men examined. In men who consumed moderate alcohol, three persons have shown Teratozoospermia in the age group of 25-35 and in heavy drinkers group, four persons in the age group of 25-35 have shown Teratozoospermia (Table 1). In men who consumed moderate alcohol, six persons have shown Teratozoospermia in the age group of 35-45 and in heavy drinkers group, eight persons in the age group of 35-45 have shown Teratozoospermia (Table 2).

\section{Discussion}

Many studies have proved the detrimental effect of alcohol on seminal parameter but its association with individual parameter is yet to be established. Alcohol causes impaired testosterone production and thereby has great impact on fertility and potency. It also has deleterious effect on sertoli cells, thereby decreasing LH, FSH production [19], [20]. Spermatogenesis is sensitive to a variety of chemical and physical stressors. Testicular hyperthermia is one such cause which has deleterious effect on male fertility since the time of Hippocrates and is a well-recognized cause of impaired sperm production [21]. In all the persons who consumed alcohol, semen color was found to be white in color. There was no change with regard to alkalinity of the semen also. 


\section{International Journal of Science and Research (IJSR) \\ ISSN (Online): 2319-7064 \\ Index Copernicus Value (2013): 6.14 | Impact Factor (2014): 5.611}

Alcohol does not seem to have a recognizable effect on these two parameters. Our study has shown decrease in the volume of semen in forty three (43) men. Men who drink moderately or heavily are more affected. It was shown earlier that excessive alcohol consumption decreased sperm volume [22], [23]. In addition, chronic alcohol intake was known to affect male fertility by decreasing sperm volume [20], [22], [24]. Martini et al found significant reduction in seminal Volume [25]. Semen volume significantly decreased in 66 drug-free alcoholics who consumed a minimum of 180 $\mathrm{ml}$ alcohol per day (brandy and whisky, both 40\%-50\% alcohol content) [23]. A significant seminal fluid volume and sperm concentration decrease has been reported in 20 men with alcohol dependence syndrome [26].

At the time of ejaculation semen is a thick gel under normal circumstances becomes liquid within 20 minutes (or 15 to 60 mins) after ejaculation. The thick gel is formed by proteins from the seminal vesicles. It was shown that liquefaction occurs only in a pH range of 6.8-8.8, at which pepsin is not active [27]. If liquefaction is delayed it will be difficult for sperm to break thick semen. Also the semen must liquefy quickly for sperm to swim out of the acidic vagina. All men examined from two different groups exhibited liquefaction time within the normal time range.

Sperm count was made in 80 alcoholics and it was observed that in fifty nine (59) alcoholics sperm count was reduced; which is quite dangerous. It was shown earlier that chronic consumption of alcohol increases oxidative stress [28]. Increased and prolonged oxidative stress causes testicular damage which impedes spermatogenesis resulting in decreased sperm count [29], [30]. Young men in the western world have a high alcohol intake, which of public health concern and could be a contributing factor to the low sperm count reported among young men [31]. In addition, chronic alcohol intake may affect male fertility by decreasing sperm count [20], [22], [24].

Sperm motility has been shown to be a good predictor of human male fertility in vivo and in vitro [32] and as such has also been found to be strongly associated with the probability of conception [33], [34]. Reduced testosterone level leads to disturbed epididymal function which results in reduced sperm motility [35]. Though testosterone was not estimated in the present study this could be contributing to reduced sperm motility. CAT (Choline acetyl transferase) is known to facilitates sperm motility [36]. Chronic alcohol intake was shown to affect male fertility by decreasing sperm motility [20], [22], [24]. Decreased sperm motility was more evident in heavy alcoholics. The alcohol affects mitochondrial functions and increases oxidative stress induced change of plasma membrane of spermatozoa, resulting in reduced motility [37]. Alcohol exposures in vitro induced reduction of sperm motility and morphology and the response is dose-related [38].

Normal sperm has an oval head and long tail. Abnormality of sperm could be defective heads/tails. If semen sample contains $4 \%$ of morphologically normal forms, it is considered fit. It is observed in this study that twenty one (21) persons in all age groups have shown morphologically abnormal sperm. In the case of semen morphology, there is a report of Teratozoospermia in $72 \%$ of heavy alcoholic persons and 63\% moderate alcoholic persons [39]. Alcohol consumption was associated with increased numbers of morphologically abnormal sperm [40]. Heavy alcohol consumption has been associated with abnormal sperm morphology [20], [38]. Alcohol has been implicated adversely to affect all sperm parameters causing oligo-, astheno- and teratozoospermia [41].

\section{Conclusion}

In this study we report that consumption of alcohol has an adverse influence on semen quality. Moderate/high alcohol consumption (4 $41 / 7 \pm 1$ units/day) was associated with an increase in morphologically abnormal sperms. Incidences of Hypospermia in 43, Teratozoospermia in 21, Oligozoospermia in 59, Oligoasthenozoospermia in 22, and Oligoasthenoteratozoopermia in 6 persons were observed. The abnormalities were more in the age group of 35-45 than 25-35 age group. It could be due to resistance of young people. Also effect was more in people who consumed more alcohol.

\section{References}

[1] W.D. Mosher, WF Pratt, "Fecundity and infertility in the United States: incidence and trends," (Editorial) Fertil Steril, (56), 192-3, 1991.

[2] WHO, "Manual for the standardized investigation and diagnosis for the infertile couple," Cambridge University Press, 2000.

[3] T.Gul, G.Yilmaz, S. Bayram, Z.N. Dolgun, S. Ege, "The effect of occupational groups and use of alcohol and smoking in thrace on semen parameters," Turkish Medical Student Journal, 7-11, 2014.

[4] NIAAA, "Tenth Special Report to the U.S. Congress on alcohol and health," Bethesda MD: NIH, 2000.

[5] CDC, "Web-based Injury Statistics Query and Reporting System (WISQARS), www.cdc.gov/ncipc/wisqars, 2008.

[6] World Health Organization, "Global Status Report on Alcohol and Health," Available at: http://www. WHO. Int/ substance abuse/publications/global alcohol report/msbgsruprofiles.pdf, 2011.

[7] H.A. Hadi, J.A. Hill, R.A. Castillo, "Alcohol and reproductive function: a review," Obstet Gynecol Surv, (42), 69-74, 1987.

[8] L.H. Kuller, S.J. May, J.A. Perper, "The relationship between alcohol, liver disease, and testicular pathology," Am J Epidemiol, (108), 192-9, 1978.

[9] R.A. Jr. Anderson, B.R. Willis, C. Oswald, L.J. Zaneveld, "Partial reversal of ethanol-induced male reproductive pathology following abstinence," Alcohol Alcohol, (20), 273-86, 1985.

[10]E. Rosenblum, J.S. Gavaler, D.H. Van Thiel, “ Lipid Pe $\neg$ roxidation: a mechanism for ethanol-associated testicular injury in rats," Endocrinology, (116), 311-8, 1985.

[11] J. Villata, J.L. Ballesca, J.M. Nicolas, M.J. Martinez de Osaba, E. Antunez, C. Pimentel, "Testicular function in asymp $\neg$ tomatic chronic alcoholics: relation to ethanol intake," Alᄀcohol Clin Exp Res, (21),128-33, 1997. 


\section{International Journal of Science and Research (IJSR) \\ ISSN (Online): 2319-7064 \\ Index Copernicus Value (2013): 6.14 | Impact Factor (2014): 5.611}

[12] P.O. Koh, M.O. Kim, "Ethanol exposure decreases cell proliferation and increases apoptosis in rat testes," J Vet Med Sci, 68(10):1013-7, 2006.

[13] E.l. Sokary, G. H, "Quantitative study on the eff ects of chronic ethanol administration on the testis of adult male rat," Neuro Endocrinol Lett, (22), 93-9, 2001.

[14] D.H. Van Thiel, J.S. Gavaler, C.F. Cobb, L. Santucci, T.O. Graham, "Ethanol, a Leydig cell toxin: evidence obtained in vivo and in vitro," Pharmacol Biochem Behav, (18), 317-23, 1983.

[15] K. Dhawan, A. Sharma, "Prevention of chronic alcohol and nicotine-induced azospermia, sterility and decreased libido, by a novel tri-substituted benzoflavone moiety from Passiflora incarnata Linneaus in healthy male rats, Life Sci, (71), 3059-69, 2002.

[16]L.J. Beckman, "Reported effects of alcohol on the sexual feelings and behavior of women alcoholics and nonalcoholics," J Stud Alcohol, (40), 272-82, 1979.

[17] G. Stutz, J. Zamudio, M.E. Santilla'n, L. Vincenti, M.F. De Cuneo et al., "The effect of alcohol, tobacco, and aspirin consumption on seminal quality among healthy young men." Arch Environ Health, (59), 548-52, 2004.

[18] World Health Organization WHO, "Laboratory Manual for the Examination and Processing of Human Semen," WHO 5th ed. Geneva, 2010.

[19]D.S. Gaur, M.S. Talekar, V.P. Pathak, "Alcohol intake and cigarette smoking: impact of two major life style factors on male fertility," Indian journal of Pathology and Microbiology, 53(1), 35-40, 2010

[20] K.R. Muthswami, P. Chinnaswamy, "Effect of chronic alcoholism on male fertility hormones and semen quality," Fertile Sterile, 84(4), 919-924, 2005.

[21] N.P. Dada R,Gupta, K. Kucheria, "Spermatogenic arrest in men with testicular hyperthermia," TeratogCarcinog Mutagen, Suppl, (1),235-243, 2003.

[22] H.J. Goverde, H.S. Dekker, H.J.Jansse et al., "Semen quality and frequency of smoking and alcohol consumption - an explorative study," Int J Fertil Menopausal Stud, (40), 135 - 138, 1995.

[23] H. Guo, H.G. Zhang, B.G. Xue, Y.W. Sha, Y. Liu et al., "Effects of cigarette, alcohol consumption and sauna on sperm morphology," Zhonghua Nan Ke Xue, (12), 2157, 221, 2006.

[24] E. Carlsen, A. Giwercman, N. Keiding et al., "Evidence for decreasing quality of semen during past 50 years," BMJ, (305), 609 - 613, 1992.

[25] A.C. Martini, R.I. Molina, D. Estofan et al., "Effects of alcohol and cigarette consumption on human seminal quality," Fertil Steril, (82), 374 - 377, 2004.

[26] K. Kucheria, R. Saxena, D. Mohan, "Semen analysis in alcohol dependence syndrome," Andrologia, (17), 55863, 1985.

[27] P.F. Tauber, L.I.D. Zaneveld, D. Propping and G.F.B. Schumacher, "A new technique to measure the liquefaction rate of human semen: the bag method," Fertility and Sterility, (33), 567-570, 1980.

[28] J.C. Kefer, A. Agarwal, E. Sabanegh, "Role of antioxidants in the treatment of male infertility," Int J Urol, (16), 449-57, 2009.

[29] O.O. Dosumu, O.B. Akinola, E.N. Akang, "Alcoholinduced testicular oxidative stress and cholesterol homeostasis in rats - the therapeutic potential of virgin coconut oil," Middle East Fertil Society J, (17),122-8, 2012.

[30]B. Eskenazi, A.J. Wyrobek, E. Sloter, S.A. Kidd, L. Moore, S.Young, D. Moore, "The association of age and semen quality in healthy men," Hum Reprod, (18),447-54, 2003.

[31] N. Jorgensen, U.N. Joensen, T.K. Jensen et al., "Human semen quality in the new millennium: a prospective cross-sectional populationbased study of 4867 men," BMJ Open, 2:pii:e000990, 2012.

[32] J. Auger, C. Serres, J.P. Wolf and P. Jouannet, "sperm motility and fertilization," ontracept. Fertility and Sex, (22), 314-8, 1994.

[33] P. Jouannet, B. Ducot, D. Feneux and A. Spira, "Male factors and the likehood of pregnancy in infertile couple, study of sperm charecterstics," International Journal of Andrology, (11), 379-394, 1988.

[34] L. Larsen, T. Scheike, T.K. Jensen, J.P. Bonde, E. Ernst, N.H. Hjollund, Y. Zhou, N.E. Skakkebæk and A. Giwercman, "Computer-assisted semen analysis parameters as predictors for fertility of men from the general population," Human Reproduction, (15): 15621567, 2000.

[35] Mohammed Shaaraway and Kamal Zaki Mahmoud, "Endocrine profile and semen characteristics in male smokers," Journal of fertility and sterility, 38(2): August, 1982.

[36] Vytas kauliskaskas et al., "Cigarette smoking and it"s possible effects on sperm," Fertility and sterility," 44(4): October, 1986.

[37] A.A. Oremosu, E.N. Akang, "Impact of alcohol on male reproductive hormones,oxidative stress and semen parameter in sprague - oawley rats," Middle East Fertility Society Journal, 20(2): 114-118, 2015.

[38] G.P. Donnelly, N. McClure, M.S. Kennedy, S.E. Lewis, "Direct effect of alcohol on the motility and morphology of human spermatozoa," Andrologia, 31: 43-7, 1999.

[39]D.S. Gaur, S. Manju, Telekar, P. Ved Prakash, “Alcoho intake and cigarette smoking: Impact of two major lifestyle factors on male fertility," Indian J Path and Microbi, 53(1): 35-40, 2015.

[40] K.J. Joo, Y.W. Kwon, S.C. Myung, T.H. Kim, „The Effects of Smoking and Alcohol Intake on Sperm Quality," Light and Transmission Electron Microscopy Findings, 40: 2327-2335, 2012

[41] NICE, "Fertility: assessment and treatment for people with fertility problems," Clinical guideline, 156, February 2013

\section{Author Profile}

Prof. G. H. Philip, BOS, Department of Zoology, Sri Krishnadevaraya University, Ananthapuramu- 515 003. Andhra Pradesh, India.

Dr. K. Pullanna, Teaching Assistant, Department of Zoology, Sri Krishnadevaraya University, Ananthapuramu- 515 003. Andhra Pradesh, India.

Dr. D. Nagalinga Reddy, Principal, Government Degree College, Penukonda, Anantapuramu, Andhra Pradesh, India. 


\section{International Journal of Science and Research (IJSR) ISSN (Online): 2319-7064 \\ Index Copernicus Value (2013): 6.14 | Impact Factor (2014): 5.611}

Table 1: Analysis of semen in men who have consumed Alcohol for more than five years

\begin{tabular}{|c|c|c|c|c|}
\hline S. No & Parameters Examined & Normal Values & $\begin{array}{c}\text { Age: } 25-35 \\
4 \pm 1^{\mathrm{a}}\end{array}$ & $\begin{array}{c}\text { Age:25-35 } \\
7 \pm 1^{\mathrm{a}}\end{array}$ \\
\hline 1 & Colour & White & White & White \\
\hline 2 & Reaction & Alkaline & Alkaline & Alkaline \\
\hline 3 & Volume & $1.5-5 \mathrm{ml}$ & $1.53 \pm 0.60$ & $\begin{array}{c}1.43 \pm 0.58 \\
(0.5-2.5)\end{array}$ \\
\hline 4 & Liquefaction & $15-60 \mathrm{~min}-2.5)$ & $\begin{array}{c}39.25 \pm 9.35 \\
(25-50)\end{array}$ \\
\hline 5 & Sperm count & $39-150 \mathrm{mill} / \mathrm{ml}$ & $28.6 \pm 10.06$ & $(15-50)$ \\
& & & $(10-70)$ & $(4-56)$ \\
\hline 6 & Total motility & $32 \%$ & $44.8 \pm 15.09$ & $32.3 \pm 13.68$ \\
& & & $(20-65)$ & $(15-60)$ \\
\hline 7 & Morphology & $4 \%$ & $3.85 \pm 0.36$ & $3.8 \pm 0.41$ \\
& & & $(3-4)$ & $(3-4)$ \\
\hline
\end{tabular}

Note: Values are mean \pm SD $(n=20)$. Minimum and maximum values are given in parentheses.

${ }^{\mathrm{a}}$ Alcohol consumed per person,Units/day.

Table 2: Analysis of semen in men who have consumed Alcohol for more than five years

\begin{tabular}{|c|c|c|c|c|}
\hline S. No & Parameters Examined & Normal Values & $\begin{array}{c}\text { Age:35-45 } \\
4 \pm 1^{\mathrm{a}}\end{array}$ & $\begin{array}{c}\text { Age:35-45 } \\
7 \pm 1^{\mathrm{a}}\end{array}$ \\
\hline 1 & Colour & White & White & White \\
\hline 2 & Reaction & Alkaline & Alkaline & Alkaline \\
\hline 3 & Volume & $1.5-5 \mathrm{ml}$ & $\begin{array}{c}1.30 \pm 0.42 \\
(0.5-2)\end{array}$ & $\begin{array}{c}1.24 \pm 0.40 \\
(0.5-2)\end{array}$ \\
\hline 4 & Liquefaction & $15-60 \mathrm{mins}$ & $\begin{array}{c}39.75 \pm 8.50 \\
(25-55)\end{array}$ & $\begin{array}{c}40.25 \pm 10.57 \\
(25-50)\end{array}$ \\
\hline 5 & Sperm count & $39-150 \mathrm{mill} / \mathrm{ml}$ & $\begin{array}{c}27.55 \pm 16.90 \\
(0-60)\end{array}$ & $\begin{array}{c}21.75 \pm 14.74 \\
(0-50)\end{array}$ \\
\hline 6 & Total motility & $32 \%$ & $34.5 \pm 14.29$ & $33.85 \pm 12.41$ \\
& & & $(0-60)$ & $(0-60)$ \\
\hline 7 & Morphology & $4 \%$ & $3.7 \pm 0.47$ & $(3-4)$ \\
& & & & $3.6 \pm 0.50$ \\
\hline
\end{tabular}

Note: Values are mean \pm SD $(n=20)$. Minimum and maximum values are given in parentheses.

${ }^{\mathrm{a}}$ Alcohol consumed per person,Units/day.

Table 3: Abnormalities observed in persons of two different age groups due to Alcohol

\begin{tabular}{|c|c|c|c|}
\hline $\begin{array}{l}\text { S. } \\
\text { No }\end{array}$ & $\begin{array}{l}\text { Addiction } \\
\text { of Alcohol }\end{array}$ & Age group in years & Abnormalities in number of men \\
\hline \multirow[b]{2}{*}{1} & \multirow[b]{2}{*}{ Group-1 } & $\begin{array}{c}25-35 \\
4 \pm 1 \text { Alcohol Units/day }\end{array}$ & $\begin{array}{c}\text { Hypospermia-8, Oligozoospermia-15, Oligoasthenozoospermia- } \\
\text { 4, Teratozoospermia-3, Oligoasthenoteratozoopermia-1. }\end{array}$ \\
\hline & & $\begin{array}{c}25-35 \\
7 \pm 1 \text { Alcohol Units/day }\end{array}$ & $\begin{array}{l}\text { Hypospermia-10, Teratozoospermia-4, Oligozoospermia-16, } \\
\text { Oligoasthenozoospermia-8, Oligoasthenoteratozoopermia-2. }\end{array}$ \\
\hline \multirow[b]{2}{*}{2} & \multirow[b]{2}{*}{ Group-2 } & $\begin{array}{c}35-45 \\
4 \pm 1 \text { Alcohol Units/day }\end{array}$ & $\begin{array}{l}\text { Hypospermia-12, Oligozoospermia-13, Teratozoospermia-6, } \\
\text { Oligoasthenozoospermia-5, Oligoasthenoteratozoopermia-2. }\end{array}$ \\
\hline & & $\begin{array}{c}35-45 \\
7 \pm 1 \text { Alcohol Units/day }\end{array}$ & $\begin{array}{l}\text { Hypospermia-13, Teratozoospermia-8, Oligozoospermia-15, } \\
\text { Oligoasthenozoospermia-5, Oligoasthenoteratozoopermia-1. }\end{array}$ \\
\hline
\end{tabular}

Hypospermia (43) : Semen volume less than $1.5 \mathrm{ml}$.

Oligozoospermia (59) : Sperm count is less than $39 \mathrm{Mill} / \mathrm{ml}$.

Teratozoospermia (21) : When less than $4 \%$ of the normal sperms show abnormal morphology.

Oligoasthenozoospermia (22) : Combination of low sperm count (less than $39 \mathrm{Mill} / \mathrm{ml}$ ) and sperm motility (less than 32\%).

Oligoasthenoteratozoospermia (6) : Combination of low sperm count, motility and abnormal morphology (less than $4 \%$ of normal forms). 